In this way we see the proper role to be played by the negative-energy states. There is an almost saturated distribution of negative-energy electrons extending over the whole of space, but owing to its uniformity and regularity it is not directly perceptible to us. Only the small departures from perfect uniformity, brought about through some of the negative-energy states being unoccupied, are perceptible, and these appear to us like particles of positive energy and positive charge and are what we call protons.

This theory of the proton involves certain difficulties, which will now be discussed. The theory postulates the existence everywhere of an infinite number of negative-energy electrons per unit volume, and thus an infinite density of electric charge. According to Maxwell's equations, this would give rise to an infinite electric field. We can easily avoid this difficulty by a re-interpretation of Maxwell's equations. A perfect vacuum is now to be considered as a region in which all the states of negative energy and none of those of positive energy are occupied. The electron distribution in such a region must be assumed to produce no field, and only the departures from this vacuum distribution can produce a field according to Maxwell's equations. Thus, in the equation for the electric field $E$

$$
\operatorname{div} E=-4 \pi \rho \text {, }
$$

the electric density $\rho$ must consist of a charge $-e$ for each state of positive energy that is occupied, together with a charge $+e$ for each state of negative energy that is unoccupied. This gives complete agreement with the usual ideas of the production of electric fields by electrons and protons.

A second difficulty is concerned with the possible transitions of an electron from a state of positive energy to one of negative energy, which transitions were the original cause of our having to give a physical meaning to the negative-energy states. These transitions are very much restricted when nearly all the negative-energy states are occupied, since an electron in a positive-energy state can then drop only into one of the unoccupied negativeenergy states. Such a transition process would result in the simultaneous disappearance of an ordinary positive-energy electron and a hole, and would thus be interpreted as an electron and proton annihilating one another, their energy being emitted in the form of electromagnetic radiation.

There appears to be no reason why such processes should not actually occur somewhere in the world. They would be consistent with all the general laws of Nature, in particular with the law of conservation of electric charge. But they would have to occur only very seldom under ordinary conditions, as they have never been observed in the laboratory. The frequency of occurrence of these processes according to theory has been calculated independently by several investigators, with neglect of the interaction between the electron and proton (that is, the Coulomb force between them). The calculations give a result much too large to be true. In fact, the order of magnitude is altogether wrong. The explanation of this discrepancy is not yet known. Possibly the neglect of the interaction is not justifiable, but it is difficult to see how it could cause such a very big error.

Another unsolved difficulty, perhaps connected with the previous one, is that of the masses. The theory, when one neglects interaction, requires the electron and proton to have the same mass, while experiment shows the mass ratio to be about 1840 . Perhaps when one takes interaction into account the theoretical masses will differ, but it is again difficult to see how one could get the large difference required by experiment.

An idea has recently been put forward by Oppenheimer (Phys. Rev., vol. 35, p. 562) which does get over these difficulties, but only at the expense of the unitary theory of the nature of electrons and protons. Oppenheimer supposes that all, and not merely nearly all, of the states of negative energy are occupied, so that a positive-energy electron can never make a transition to a negativeenergy state. There being now no holes which we can call protons, we must assume that protons are really independent particles. The proton will now itself have negative-energy states, which we must again assume to be all occupied. The independence of the electron and proton according to this view allows us to give them any masses we please, and further, there will be no mutual annihilation of electrons and protons.

At present it is too early to decide what the ultimate theory of the proton will be. One would like, if possible, to preserve the connexion between the proton and electron, in spite of the difficulties it leads to, as it accounts in a very satisfactory way. for the fact that the electron and proton have charges equal in magnitude and opposite in sign. Further advances in the theory of quantum electrodynamics will have to be made before one can deal accurately with the interaction and see whetherit will settle the difficulties, or whether, perhaps, a new idea can be introduced which will answer this purpose.

\title{
Physiological Effects of Work in Compressed Air.
}

THE average man always finds it surprising that our bodies can support such atmospheric pressures as $100 \mathrm{lb}$. per sq. in. without the slightest derangement of the delicate structures and processes on which life depends, but that, owing to a secondary effect, the return to normal pressure is accompanied by grave risk. A sojourner in compressed air inevitably soaks up a considerable volume of the nitrogen of the air into simple solu- tion in the tissues and fluids of his body. So long as the pressure is maintained this gas remains hidden and harmless, but any reduction of pressure will drive it out of solution. The critical time in the management of compressed air workers is the period of decompression when they are passing from high air pressures down to the normal. Given time, the blood will carry off the excess gas and discharge it to the atmosphere in the lungs as the 
pressure falls, but a rapid decompression overloads the blood with excess gas, which bursts out in the form of bubbles and chokes the circulation with froth.

Compressed air is used by engineers to keep back water in sinking the foundations of bridges and in tunnelling under rivers; besides the men engaged in such work, divers using the ordinary rubber dress have to breathe air at high pressures. The joint discussion between the Sections of Engineering and Physiology of the British Association at Bristol attracted leading exponents of practice and theory in both these lines of work. Although divers are fewer in number than tunnel workers and their occupation is of less public importance, most of the recent research and experimental work has been directed to their special circumstances, and those responsible for diving work have been quick to take advantage of any new knowledge. An outstanding example is the action of the British Admiralty in being the first to adopt the entirely novel system for conducting the decompression which was devised by Prof. J. S. Haldane and has since been taken up by most of the navies of the world. Its value for divers has now been established by twenty-five years' experience, and particularly in some recent salvage operations where more than five thousand dives were made at pressures between $50 \mathrm{lb}$. and $60 \mathrm{lb}$. per sq. in. without accident.

The circumstances of tunnel workers differ from those of divers in that they have to work much longer shifts under pressure, though the pressures themselves are never so high as those experienced. by divers. In times past the mortality among the tunnel and caisson workers from compressed air illness was so heavy that many countries adopted State regulations designed to protect the men by limiting the length of shift and enforcing some sort of gradual decompression. Undoubtedly these regulations have done good, but in the light of modern knowledge and experience they could be improved so as to give greater security to the men while avoiding the costly waste of working time resulting from some of their clauses.

If the civil engineering of the future is going to call for higher pressures than the $40 \mathrm{lb}$. or $45 \mathrm{lb}$. per sq. in. that has been the limit hitherto, it is certain that these rules will be found badly wanting, and Sir Ernest Moir in opening the discussion indicated that the time has come for concentrating the available knowledge and experience in producing a rational and practicable code or system for the use of engineers charged with the control and safety of workers in such air pressures. One of the difficulties of the matter is that there is a very great difference in the susceptibility to compressed air illness of different individuals, which at present can only be discovered by trial, so that cases of illness are still to be expected under a system which is quite safe for the average man. Fortunately, a cure is available in 'recompression', which if applied sensibly and at once is certain. Sir Ernest Moir, by his introduction and employment of the ' medical air lock' for applying this treatment, has been the means of saving many hundreds of lives.
Dr. M'Master, who described the latest British experience at the Silent Valley dam of the Belfast waterworks, mentioned many points which seemed to show that secondary factors, such as the temperature and humidity of the workings or a slight vitiation of the air supply, which would be unimportant in diving work, made a marked difference in the number of cases. In the sea we have a continuously graded range of hydrostatic pressures through which the diver can be decompressed as he gradually ascends, but in caisson work the pressures can only be roughly adjusted to the theoretical requirements, so that, though all serious illness was prevented, a good many minor but painful cases of 'bends' had to be treated by recompression, and to cure them it was found necessary to recompress many of the patients to $5 \mathrm{lb}$. above the pressure at which they had been working (about $35 \mathrm{lb}$.). This contrasts strangely with experience of divers working at $50 \mathrm{lb}$. pressure, who when they develop similar symptoms are nearly always cured by recompression to a mere $15 \mathrm{lb}$. or so, which greatly simplifies and shortens the treatment. But divers, being on board ship, are generally treated immediately the symptoms appear, while men on engineering work may have time to get home before they become ill and then may not present themselves for treatment for some hours. This probably underlies the difference, and the point illustrates one of the difficulties of the engineer; he cannot very well insist on a shift of a hundred men hanging about round the works for an hour or two after they have finished work for the day on the off chance that one of them may develop compressed air illness, but the salvage officer with his handful of divers can easily arrange for there to be no means of getting ashore until the danger period is past.

Mr. Davis, jun., in the course of an interesting review of the history of the subject, described apparatus lately introduced by Messrs. Siebe, Gorman and Co. for very deep diving, including a large steel pressure chamber which is lowered under water so that the diver can enter it on the completion of his job and be hoisted inboard without releasing the air pressure from his body. A long decompression can then be conducted in warmth and dryness instead of under water with much discomfort and fatigue as hitherto, while the ship is free to slip her moorings and get clear or fire blasting charges, which could not otherwise be done until the diver's decompression was finished.

Sir Leonard Hill and Commander Selby spoke of the experimental diving which has been carried out for the Admiralty to more than $300 \mathrm{ft}$. or 130 lb. pressure, using the Davis decompression chamber and other special devices. One unexpected and rather awkward finding was that, though all the divers were picked men who had been put through a specially searching medical examination, some of them became abnormal mentally (or emotionally as Sir Leonard Hill put it) whilst under this high pressure, and on their return to the surface could remember nothing of what they had been doing before they began to ascend. This effect

No. 3181, VoL. 126] 
might be attributed to the high partial pressure of oxygen in pure air when breathed at $130 \mathrm{lb}$., or to impurities in the air which was actually supplied to the divers, but Sir Leonard Hill has made tests on the same men which satisfy him that neither oxygen nor carbon dioxide is responsible. It seems to be an extreme case of the subtle change in character and behaviour which comes over some men at less high air pressures and is well known to experienced diving officers. Divers affected in this way generally keep fairly quiet on the subject, as they do not wish to be thought excitable or foolish about their work. The steel decompression chamber was employed to great advantage in these experimental dives, but, as Prof. Haldane pointed out in concluding the discussion, the stages of decompression given to the men were not calculated on the principles which have proved so satisfactory hitherto and do not appear to have given sufficient margin of safety. This is a matter which can easily be rectified if necessary without invalidating the ingenious methods and appliances which have been elaborated for this extremely difficult sort of diving.

The Italian divers now working on the wreck of the Egypt at a depth of 400 feet have cut out all danger of compressed air illness and the need for a host of hampering precautions by using the Neufeldt and Kuhnke armoured apparatus, which, though flexibly jointed, sustains the enormous hydrostatic pressure of $1701 \mathrm{~b}$. per sq. in. corresponding to that depth and enables the man inside to breathe air at atmospheric pressure. The gain in safety and economy of working time which results is partly offset by a loss of mobility and manual efficiency as compared with a rubberdressed diver, but this again is compensated by the elaborate grabs and machinery of the salvage ship. The diver on the bottom has become less the working agent and more the eye and brain directing engines which are lowered to him and worked from above. Conceivably some such semi-automatic system of working may develop in caisson and tunnel work, though it does not seem called for with the pressures likely to be used in the near future. None of the speakers expressed any doubt that all serious illness could be prevented by suitable decompression: the real problem is to key these lengthy decompression periods in with the design of the tunnel, the scheme of work, and the system of shifts, so that they may become something less wasteful and unsatisfactory than hours of enforced idleness passed in dismal steel cylinders.

G. C. C. Damant.

\section{Centenary of the Royal Geographical Society.}

$\mathrm{T}^{\mathrm{H}}$ E Royal Geographical Society will celebrate on Oct. 21 and the two succeeding days its centenary of inauguration. The Duke of York will open the proceedings on the afternoon of Oct. 21, and delegates from the Société de Géographie, of Paris, and the Gesellschaft für Erdkunde, of Berlin, both of which have already celebrated their centenaries, will present addresses. In the evening, Sir Charles Close, president, Mr. Douglas Freshfield, Sir Francis Younghusband, the Marquess of Zetland, and Dr. H. R. Mill will speak on the history of the Society. On the mornings of Oct. 22 and 23, a series of short papers on "The Habitable Globe" will be read by British and foreign geographers, and in the afternoon of Oct. 23, another series on "Incidents in the History of Exploration" will be read by Lord Lugard, Sir Martin Conway, Sir Francis Younghusband, Sir Halford Mackinder, Col. H. Bury, Mr. J. M. Wordie, and others. The centenary dinner of the Society, at which the Prince of Wales will preside, is to be held on Oct. 23.

Enjoying, on Dec. 31, 1929, the enviable roll of 6369 members, inclusive of 679 women, the Royal Geographical Society emerges from one hundred years of vicissitudes a successful and vigorous English institution. Among our readers there must be some of an earlier generation privileged to retain contemporary recollections of intercourse with intrepid pioneer discoverers who, in their day, lifted the veil in fields of the Society's operations--of, for example, John Rae, Erasmus Ommanney, McClintock, Inglefield, Nares, Leigh Smith; of John Kirk, Grant, Burton, Joseph
Thomson. To these elders the centenary proceedings should, for this reason, bring especial interest and point.

Space would not permit notice here of the position of geographical knowledge among the nations at the time of establishment of our home-born organisation. Most of us know, however, that in the early years of the nineteenth century, science was moving definitely towards co-operative effort and in departments-its horoscope was cast that way, though no seer maybe could have forecast our present-day delimitations and specialisation. There sprang into existence new bodies-offshoots of the parent Royal Society-and with each that institution observed terms of amity, though Banks was, perhaps, an unduly obstinate element. Among such were the Geological Society (1807), Institution of Civil Engineers (1818), British Association (1831). As regards individual effort and consequent influence on thought, it is useful to recall that Lyell published the first volume of his "Principles of Geology" in 1830; that year witnessed also the issue of Charles Babbage's argumentative "Reflections on the Decline of Science in England ".

Already, however, in the geographical domain, Paris had instituted the Société de Géographie (1821) ; Berlin, the Gesellschaft für Erdkunde (1828). There was at this period half a world of unknown tracts of land to conquer. All Europe, too, was discussing the achievements of Baron Alexander von Humboldt, traveller and naturalist. This illustrious geographer, welcomed constantly in English philosophical circles, had been elected

No. 3181, Vor. 126] 